\title{
RELATIONSHIP BETWEEN REACTION TIME AND AMPLITUDE CHANGES OF THE H-REFLEX IN THE PERFORMANCE OF SIMPLE MOTOR TASK IN PATIENTS WITH THYROTOXICOSIS
}

\author{
Miroslav Marinov ${ }^{1}$, Iglika Marinova ${ }^{2}$, Kosta Mirchev ${ }^{3}$, Borislav Boychev ${ }^{4}$, \\ Christiana Romanova ${ }^{2}$, Nina Radeva ${ }^{5}$, Radko Zl. Radev ${ }^{1}$ \\ 1) Department of Preclinical and Clinical Sciences, \\ 2) Department of Hygiene and disaster medicine, \\ 3) Department of Physiology and Pathophysiology, \\ 4) University Hospital - Varna \\ 5) Department of Health Management, \\ Medical University - Varna, Bulgaria.
}

\section{SUMMARY:}

The authors examine the dependence between reaction time as an indicator of change at cerebral level and H-reflex amplitude change being a relative index of excitability level in the spinal cord during the preparation of a simple voluntary movement in thyrotoxicosis patients. Electrophysiological investigations are carried out after identifying the disease and prior to the beginning of causal therapy. Patients are comfortably seated on a chair in a dark room and respond to light signal from a blitz-lamp and it was determined reaction time. Simultaneously with light signal presentation, nervus tibialis in the popliteal fossa of the same leg is excited to evoke H-reflex. One-day signal programme consists of a total of 120 light signals divided into three equal blocks. H-reflex amplitude evoked only once for every light signal is compared with control H-reflex amplitude. Its decrease or increase is read. Reaction times are grouped according to the extern of corresponding $\mathrm{H}$ reflex amplitude increase or decrease. Data obtained serve to construct relation curve between reaction time and $\mathrm{H}$ reflex amplitude changes. This relation curve differs in nature from the curve when healthy subjects under the same experimental conditions are tested.

Key words: reaction time, H-reflex amplitude change, thyrotoxicosis, voluntary movement.

\section{INTRODUCTION:}

Thyrotoxicosis as a disease leading to a number of movement disorders has long attracted the attention of electrophysiologists. Many authors have studied the changes in EMG and H-reflex, $M$ response, and have studied in detail a number of changes occurring at the level of brain and spinal cord, and then search the relationship between them. Starting from the classical works $(1,10)$, and modern authors $(2,3,5,7,18,24)$ that the function of spinal neurons is under permanent control of suprasegmental structures, we investigated the relationship during the preparation of a volitional movement between: reaction time (RT) - an indicator of changes in the level of the brain, and amplitude changes of the $\mathrm{H}$ reflex (H-r) - an indicator of the level of reflex excitability of suprasegmental apparatus of the spinal cord in individuals of different sex, age $(8,9)$ and in patients with neurosis. The characteristic curves, which are expression of this dependence, and literature that change the H-reflex of patients with thyrotoxicosis (16), made us look for correlation between RT and N-r in the performance of simple motor task in these patients, which was the aim of this study.

\section{MATERIALS AND METHODS}

Studies conducted on patients with thyrotoxicosis and the diagnosis is made based on history, clinical examination, hormonal dosage, ultrasound of thyroid gland and others (Tabl. 1.).

Table 1. Indicators of hormonal dosage in patients with thyrotoxicosis

\begin{tabular}{|c|c|c|c|c|c|}
\hline № & Name & Age & $\begin{array}{c}\text { History of } \\
\text { the disease }\end{array}$ & $\begin{array}{c}\mathrm{T}_{3}(0.5- \\
2.0 \mathrm{nmol} / \mathrm{l})\end{array}$ & $\begin{array}{c}\mathrm{T}_{4}(70- \\
150 \mathrm{nmol} / \mathrm{l})\end{array}$ \\
\hline 1. & I.M.K. & 55 & 125 & 2.0 & 206 \\
\hline 2. & J.I.R. & 31 & 2749 & 2.8 & 170 \\
\hline 3. & S.P.A. & 32 & 912 & 3.5 & 300 \\
\hline 4. & Z.V.Ch. & 36 & 8219 & 2.75 & 270 \\
\hline 5. & V.A.N. & 43 & 7966 & 3.4 & 250 \\
\hline
\end{tabular}

After establishing the diagnosis and before thyreostatic treatment for each person we had a two-day experimental study. Observed patients were with mild 
thyrotoxicosis (excluded from the study were patients with thyrotoxicosis of heart absolute arrhythmia and thyrotoxicosis myopathy). Patients sat comfortably in a chair in a dark room and they responded to the light of blitz lamp fed through a red filter. The engine response to the preliminary instruction was to lift a maximum speed of the heel of right foot (plantar flexion) of a button mounted on the platform floor. The button was connected to the frequency ChS-2, which recognize the duration of RT. Frequency is released synchronously with the bringing of the light signal and is stopped by lifting the heel of the foot from the button. Along with prior submission of a light signal we annoyed the $\mathrm{n}$. tibialis in popliteal fossa in the same leg of the H-evoked reflex a rectangular pulse with duration $1 \mathrm{~ms}$. The amplitude of evoked muscle response was $30-50 \%$ of the maximum amplitude of the H-reflex by M-sought answer to be singled out only. Irritation we made with sound "Multistim Diza". The H-reflex, recorded from the oscilloscope "Diza-51 B 00" to photographic film, was removed of lateral head of $\mathrm{m}$. gastrocnemius on the right leg which was willed agonist of the forthcoming movement. One-day program consisted of 120 light signals, divided into three groups of 40. Before and after each block we evoked four times $\mathrm{H}$-reflex without light signal. The average amplitude of these H-reflex we took as control H-reflex at rest. Comparing the amplitude of evoked once for each light signal with H-reflex amplitude of the control H-reflex aware of its decrease or increase. RT grouped according to what is the reduction or increase of a corresponding H-reflex. From the data we construct the dependency graph RT (on ordinate) / H-r (on abscissa).

\section{RESULTS AND DISCUSSION:}

The survey data are presented in Fig. 1. Immediately impressed wide "dispersion" of the amplitude changes than fivefold decrease to 1.6 times increase compared to control. RT in the range 180 to $300 \mathrm{~ms}$ No statistical accuracy between RT individual dots. The curve of dependence RT / $\mathrm{H}-\mathrm{r}$ is almost parallel to the $\mathrm{x}$-axis. Quite different is the curve found in healthy men $(8,9)$, there is a specific type of parabola (Fig.2.).

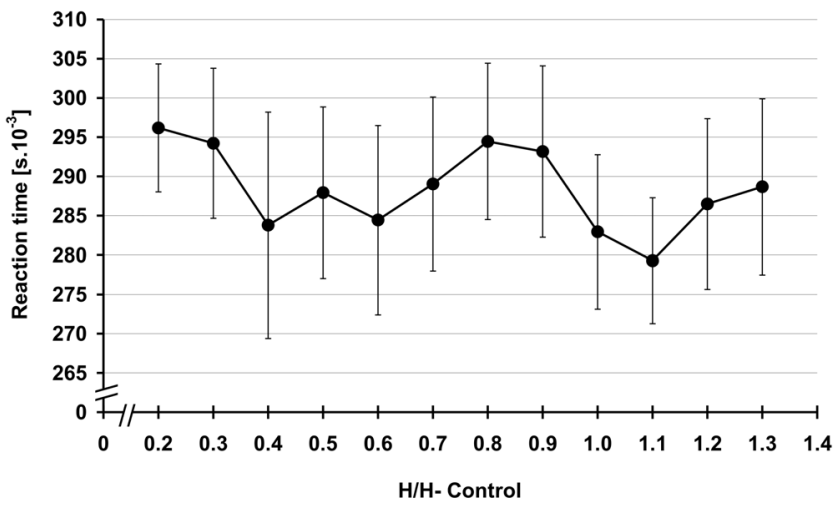

Fig. 1. Average reaction time of patients with thyrotoxicosis, expressed as a function of amplitude changes of the H-reflex, taken from the lateral head of $\mathrm{m}$. gastrocnemius of the right leg ( $\mathrm{H}$ to $\mathrm{H}$ control). The movement is plantar flexion of the right foot. Confidence interval of the mean, indicated by a vertical line at each point was calculated at $\mathrm{p}=0.05$.

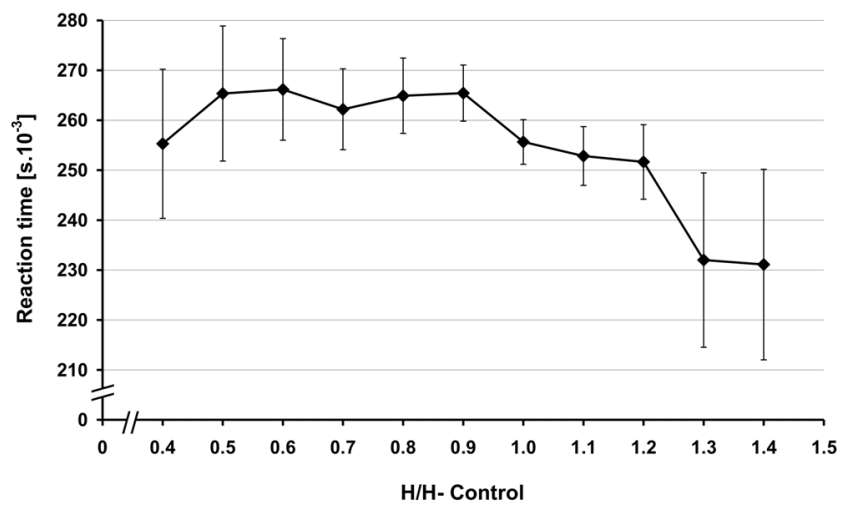

Fig. 2. Average reaction time of healthy volunteers expressed as a function of amplitude changes of the H-reflex, taken from the lateral head of $\mathrm{m}$. gastrocnemius of the right leg ( $\mathrm{H}$ to $\mathrm{H}$ control). The movement is plantar flexion of the right foot. Confidence interval of the mean, indicated by a vertical line at any point was calculated at $p$ $=0.05$.

The lack of dependency characteristic of thyrotoxicosis patients could be associated with several alternatives. The discussion of myopathic disorders in thyrotoxicosis, changing the number of recruited motor units (and the number of recruited muscle fibres entering a motor unit) is unlikely because they affect mainly the proximal muscles $(4,15,17,19,23)$ and our patients are at an early stage of disease when it is rarely possible occurrence of these changes. More likely is that it is a violation of the tactics of the motor response in these patients and hence to its preparation, more so in the course of trials found that after the first block of 40 signal occurs a reduction of attention found by us at the number of errors in extension of RT. Maybe supraspinal control quickly loses position and the increased excitability of these patients. On the other hand, the impact on the amplitude of the H-reflex from preand postsynaptic effects $(6,20)$, and $\Gamma$-motoneurons (14) which change with supraspinalni effects gives a change of attitude RT / H-r. Thirdly, is possible influence of the CNS, which is associated with involvement in disease ofmotoneurons - thyrotoxic encephalopathies $(11,21)$ and neuropathies $(12,13,22)$ from the toxic effects of increased thyroid hormone. 


\section{CONCLUSION:}

The curve of dependence RT / H-r in nature is different from the curve for the same subject obtained in the study of healthy subjects in similar experimental situations. This could serve as an early diagnostic method to identify the disease in its early stages.

\section{REFERENCES:}

1. Granit R. The Basis of Motor Control. London: Academic Press. 1970.

2. Sherrington CS. The integrative action of the nervous system. New York: Arno Press. 1973.

3. Gurfinkel VS, Palcev EI. The influence of the state of the segmental apparatus of the spinal cord to the implementation of a simple motor response. AS USSR. 1965; 10 (5): 855859. [In Russian].

4. Gurfinkel VS, Kotz JM, Krinskii VI, Palcev EI, Feldman AG, Tzejtlin ML et al. On the set before the movement. In: Models of structural-functional organization of certain biological systems. Moskva: Nauka. 1966. pp. 292301. [In Russian].

5. Kotz JM. Organization of voluntary movement. Moskva: Nauka. 1975. [In Russian].

6. Gurfinkel VS, Levik US. The central programs and a variety of movements. In: Management movements. Mitkin AA, Pika G. eds. Moskva: Nauka. 1990. pp. 32-41. [In Russian].

7. Requin J. Some data on neurophysiological processes involved in the preparatory motor activity to reaction time performance. Acta Psychol (Amst). 1969; 30: 358-367. [PubMed].

8. Lanska DJ. Chapter 33: the history of movement disorders. Handb Clin Neurol. 2010; 95: 501-546. [PubMed].

9. Tzekov Tz, Gerilovski L. Relationship between the amplitude of the H-reflex of muscle agonists and latency of motor response in terms of simple movement situation. V Sci session of MF. Varna 1974. pp. 72-75. [In Bulgarian].

10. Tzekov TzT. Relationship between reaction time and spinal changes in preparation for voluntary movement. Ph.D. dissertation. Varna. 1975. [In Bulgarian].

11. Norris FH Jr. Satus of the segmental inervation in thyrotoxic periodic paralysis. Electroencephalogr Clin Neurophysiol. 1966; 21 (1): 67-70. [PubMed].

12. Zefirova GS, Mahneva IM, Kochergina II, Plevako VA. Apatetic form of hyperthyroidism. Klin medicina. 1998; №7: 48-49. [In Russian].

13. Havard CW, R.Campbell ED, Ross HB, Spence AW. Electromyographic and histological findings in the muscles of patients with thyrotoxicosis. $Q J$ Med. 1963; 32: 145-163. [PubMed].

14. Ramsay ID. Electromyography in thyrotoxicosis. Q J Med. 1965; 34: 255267. [PubMed].

15. Tajima K, Mashita K, Jamane T. Thyrotoxic myopathy associated with subacute thyroiditis. Clin Endocrinol (Oxf). 1984; 20 (3): 307-312. [PubMed].

16. DeGirolami UU, Smith TW. Teaching monograph: pathology of skeletal muscle diseases. Am J Pathol. 1982; 107 (2): 231-276. [PubMed].
[FullText].

17. Person RS. Some modern way of an analytical study of human neuromotor apparatus. Fiziol cheloveka. 1982; 8 (6): 1018-1033. [In Russian].

18. Gurfinkel VS, Kotz JM. Shik ML. Regulation of human posture. Moskva: Nauka. 1965. [In Russian].

19. Gurfinkel VS, Kotz JM. Motor presetting in humans. In: Neural mechanisms of motor activity. Moskva: Nauka. 1966. pp. 158-165. [In Russian].

20. Bassi S, Albizzati M, Beltramelli A, Fratolla L. Encephalomyelitis with Thyrotoxicosis. J Neurol (Berl). 1978, 218 (4): 293-295. [PubMed].

21. Milanov I, Sheinkova G. Clinical and electromyographic examination of tremor in patients with thyrotoxicosis. Int J Clin Pract. 2000; 54 (6): 364-367. [PubMed].

22. Pollard JD. Neuropathy in diseases of the thyroid and pituitary glands. In: Peripheral neuropathy. Dyck PJ, Thomas PK. eds. New York NY: Oxford University Press. 2005: pp. 20392042.

23. Feibel JH, Campa JF. Thyrotoxic neuropathy (Basedow's paraplegia). $J$ Neurol Neurosurg Psychiatry. 1976; 39 (5): 491-497. [PubMed]. [FullText].

24. Hallett M, Tandon D, Berardelli A. Treatment of peripheral neuropathies. $J$ Neurol Neurosurg Psychiatry. 1985; 48 (12): 1193-1207. [PubMed]. [FullText].

\section{Corresponding author:}

Radko Zlatkov Radev, MD, PhD

Department of preclinical and clinical medicine, Medical University of Varna "Prof. P. Stoyanov"

Tel: +359/52 677051

E-mail: pathophysiology@mu-varna.bg; 